\title{
The Technology Standards among Dentistry Faculty Members in University of Mosul
}

\author{
Abdul -Haq A. M. Suliman (PhD) \\ Professor \\ Department of Conservative \\ Dentistry
}

\author{
Reem A. Al-Jarrah (PhD) \\ Lecturer \\ Department of Basic Sciences
}

\author{
Mohammed N. Ahmed \\ Assistant Lecturer \\ Department of Basic \\ Sciences
}

College of Dentistry

\begin{abstract}
The present study shows the description on the situation of Dental Faculty members in 2004, in terms of the development of the concept of the Information Technology (IT). The strategy of questionnaires has been treated in this study to see the aspects of training needs responded by the faculty members and what type of the modules they seek to take. The study hypothesized that the academic staff in the faculty is in need for refresher courses, workshops and various seminars in the field of IT as a result of the global development in their fields of study and application. The study also provides a formal description to the effect of the IT, the computer implementation and web-site links in the fields of academic research. The study concluded that IT is habitually an essential template in order to develop the individual and academic abilities on the one hand and to keep coming with the excessive progress in the computerized information systems in the worldwide as well as the urgent need to develop the techniques of the academic teaching in the college.
\end{abstract}

$$
\text { المستويات التقنية لأعضاء الهيئة التدريسية في كلية طب الأسنان - جامعة الموصل }
$$

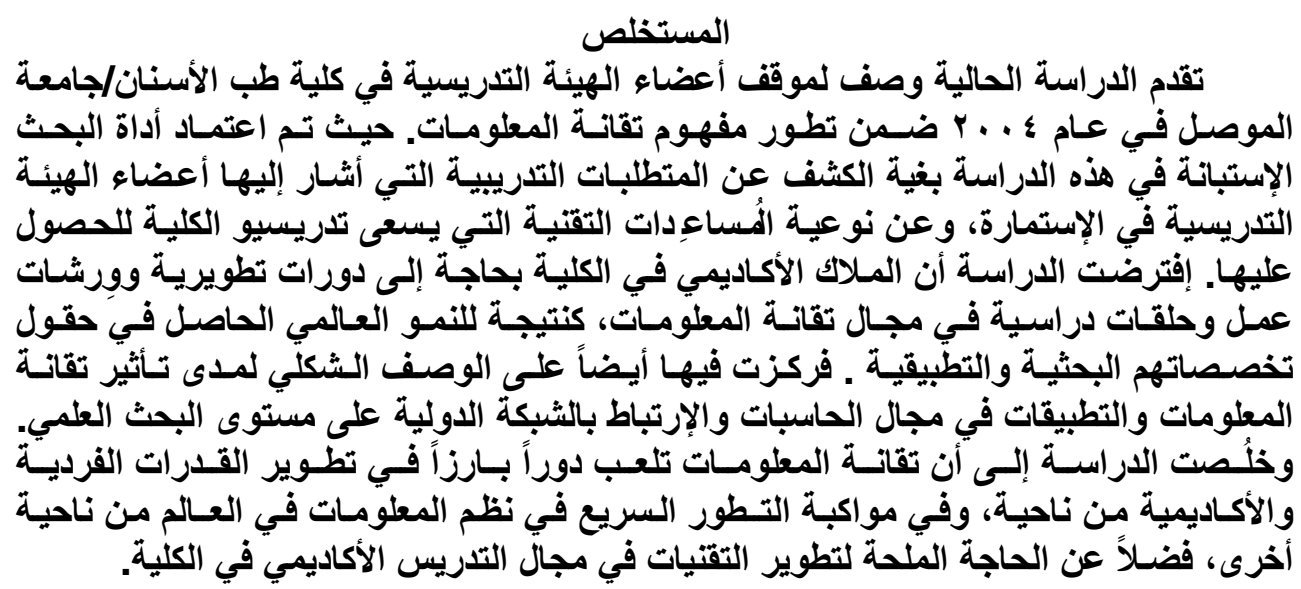




\section{Introduction}

The broad vision about the employment of IT is still incomprehensible yet. The methods and training capabilities are habitually traditional and hardly keep coming with the modern methodology of computer training abilities. In this respect, it is essential that to recognize the most significant varieties of the overall data of the (IT) to keep modernize the teaching methods in the specialized aspects of knowledge in the academic fields. This study raises the main points that should be taken into consideration in order to map out the strategy of developing the faculty the members in the academic level as well as to illuminate the access of analyzing the qualitative and quantitative construes of the academic members. During the $3^{\text {rd }}$ millennium, the world has witnessed an overwhelming progress in IT. One of the magnificent innovations is the computing IT and the new training methods of knowledge that is based on the information of human mind and artificial intelligence. Throughout the statistical analysis, one can deduce that the major constraints which hinder the faculty member to achieve their academic targets. This issue annexes the faculty members with their various scientific backgrounds, academic posts, age groups and different conceptual categories.

IT is the access to all the facilities available in the modern communication and utilizes the ability of an individual to work independently in terms of a modern knowledge basis. This can be recognized via the application of the technical academic standards in the field of specialization to use mechanics, electronics, tools, resources, processes, and systems responsibly to access and evaluate information in any medium. The use of information is to solve problems, training study research, communicate clearly, make informed decisions, and construct a new knowledge of data - base, products, or systems (cf. Fortier, et al. 1998, 1). The IT standards are grouped into four axioms or content standards specifying what academic members should know and be able to perform. The first two content standards focus on technology use and data processing skills. The latter two axioms build upon these by adding performance standards that deal with attitudes, appreciation, independent learning, teamwork skills, and personal and social responsibility. Designing and managing dental clinical radiology, laboratory or hospital information systems $\left({ }^{*}\right)$.

$\left(^{*}\right)$ This study was conducted in terms of Mississippi Consortium questionnaires managed on the faculty members of Mosul Dentistry College. They are manipulated by the researchers as reference for the current study. The questionnaires had been prepared by Mississippi Consortium and the respondents were Dental Faculty members/University of Mosul. The analyses, statistics, discussions, schedules, figures, tables and results were done by the researchers themselves. 
Hence, the study (according to the nature of the questionnaires) hypothesizes four axioms of IT to be analyzed:

1. Demographic Information: this axiom includes sexes, age groups the variety of ages among the faculty members. This aspect helps in showing the most reliable assessments about the points of existing shortages in the faculty and to observe the performance of the members periodically.

2. Academic Information and Needs: the respondents included in this study are affiliated to the Dental Faculty at Mosul University. Most of the respondents showed their opinions via the questionnaires in order to estimate the standard deviation of the teaching years; the technical information aided the academic operation in the Faculty and the performance requirements of the teaching staff and the researchers.

3. Training Information and Needs: this axiom is per se gist of the study to construe the prerequisites of the academic staff to keep coming with the modern technologies. The faculty respondents would like to receive an additional training via enrolment and/or workshops. The most reliable choices selected by the respondents the computer-Aided Design, DataCollection and Analysis, Computer Modeling, Developing Online Courses etc

4. Information Technology and Needs: this aspect is done in the field of computer usage systems and the flexibility of accessing the network in the Faculty or in the University in general. This axiom indicated the average time of using computerizing modules such as Internet and e-mail services. The respondents may vary with respect to their responds and answers; some refer that they can get the access from their offices, while others said that they have exposure to the web-site from their homes etc. This axiom focuses on the IT in the teaching discipline and to use the IT resources in the academic operations especially multimedia software in the classrooms, video conferencing and audio visual aids. The research requirements can be intercepted with IT resources such as spreadsheet, statistical data, web-page development etc.

\section{Theoretical Background}

IT provides many exciting applications for the health sector, such as computer-aided academic training such as oral surgery, the use of talent methods to examine patients from their homes, and patient/doctor interaction via the Internet and digital medical libraries. IT tools can provide the health care sector with unprecedented productivity and quality of care if there is a strategic vision and adequate research to ensure success (Cf. Reddy, et al., 2001,1). 
The modern statistics provides the research workers with the quality and quantity of certain thing. It is an important field of study to get aquatinted with the validity and efficacy of certain phenomenon and /or strategy adopted in any institutional field. It is rapidly a growing subject with much original material still not available in the in the topics. It grows as statisticians to find answers to more and more of the problems and obstacles posited by research workers and/or questionnaires in order to find suitable solutions with their recommendations on a logical and rational bias. Those who are among the earliest contributors to statistics are productive by which the new customers can find diverse opportunities for their research talents to focus on the leakages and shortages in the institution. In the application of statistics, principles are the general points even though techniques may differ, and the need for training in statistics and IT grows as an increased application is made in the biological and social sciences, medical resources, engineering and industry (Steel and Torrie, 1981,11).

Hence, IT can also help to provide better feedback loops for connecting providers, policymakers, patients with late-breaking research and discussions about clinical decision-making policy. Only IT can help us to take data from records of individual care and make them available for analysis of populations and help in diagnosing the delicate diseases (cf. Reddy, et al., 2001,2).

The basic principles that make the research more scientific in its nature are the observation; it is the raw material for the researchers through the history of the disease etc. As for the information to be applicable to these observations, they must be in the form of numbers, symbols, graphs, diagrams, schedules etc. If we want, for instance, to improve the quality and the acceptability of computation in the certain faculty, we may observe the methods of using computation and web access. Collecting data is prerequisite as well to make an image on the case-study and verifying the frequent use. Putting a strategy of analyzing these data on an objective (not subjective) bias is requested to come up with the results and conclusions. The results are to be mapped out with the findings, conclusions, and finally the recommendations. In this way of the scientific research we can come with a precise evaluation on the applicable information statistical method.

\section{The Rationale of Information Technology}

New information technologies have the potential to dramatically improve our academic health training system as it exists nowadays. IT can help to ensure that the health-related information and services are available any time and anywhere, permit health care practitioners to access patient information wherever it may be located, and help researchers better to understand the human body, share information, and ultimately develop more beneficial treatments to keep patients healthy. Implementing the 
recommendations made in the reports would represent a major step toward realizing the potential of IT to increase every patient's access to the quality health care and to decrease the cost of care delivery. The institutions has a unique role to play in supporting research in this critical area and in coordinating its own cross - agency activities in the application of IT to health care (Reddy, et al., 2001, 17).

The researcher's first concern is the gist of data that are whether it is to be considered as all possible data or as a part of larger body. It is of the great importance to make a clear-cut distinction whatsoever between the resulted information of the loose thinking on the one hand and the writings on that aspect of knowledge templates on the other. A sample should be directed towards the corpus data that are possibly inferred according to the rules of mechanical items in collecting data. The strategy of IT should be representative in order to be manifested in the qualitative and quantitative spectrums. To obtain a representative sample, we should embody the hypothesis in terms of rules of the drawing sampling items and the principles of randomness. Randomness is however the result of a mechanical process intended to ensure the individual subjective biases, either known or unknown in nature, then make them objective ones. The hypothetical samples are subjective in the observation process, while in the theoretical implication, verification, data analysis, results and findings processes; they should be inhibited on the logical objective nature of the research and information techniques. As a consequence, the laws of the probability and hypothetical criteria applied on the context of the current affairs via questionnaires or case study. The calculations and evaluations applied on the cases under discussion, which show the varieties called variables and/or random variables. That is why the variables in their nature are either qualitative or quantitative in the IT. The privacy and data collection about the IT is concerned with the justification of the claims to limit the access to the personal information. There are various grounds on which the person can argue the constraints should be placed on the dissemination, processing and acquiring the individual information. The standard issues in computing the information and communication technology seem to have little in common. The range from the desirability of software patents to the acceptability of the communication channels need for a generic privacy to the prospects and to the top-level domains. IT draws our attention to the moral questions at the intersection of institution, morality and epistemology. It raises several questions such as: Are we responsible for what others and we know or believe and are we also responsible for the design of our electronic artifacts and the software efficacy? Do we have responsibilities to make others believe certain things in certain situations? Is it permissible for our knowledge base and that of the 
others in such a way that we can no longer be held accountable for what we do or think? (Hoven and Lokhorst, 2004,378).

The quantitative variable is one for which the resulting observations can be measured because they possess a natural order or ranking technology. In this mapping the variables includes the values that are in some range possible such as heights, weights and numbers. The evaluation of performance degree is made by certain individual/s of the institution. The provider organization (i.e. the academic faculty that is to be the information and scientific provider) lack the information about the efficiency of IT solutions in terms of both cost and quality, making it difficult for them to make decisions about the IT investments. It is nowadays stated that the computer - based patient records can substantially improve patient care, outcomes, and costs in the dental fields via the history of the cases that may uncover the diagnostic tools of the case (Cf.) الطويل)

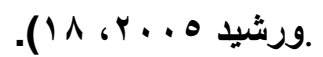

IT helps in reducing the diagnostic uncertainties and improve the clinical decision - making by using computing techniques and dental informatics, for instance developing the clinical decision making tools for determining the probability that the patient with dental pain actually has acute decay and should be admitted to rule out of dental treatment designing interactive consultation system to treat patients more efficiently and cost effectively via using health database referencing to a broad range of clinical experiences and pertinent variables. IT therefore aims at developing the transportable software systems for image reconstruction and for 3-D visualization and analysis of dental imaging data (Hutton, et al., 2000).

\section{The Clinical Applications in Dental Informatics}

The clinical applications include a wide range of using devices and software programs that contains an electronic oral health record of dental and medical history( $\left(^{*}\right)$, treatment planning, charting of oral status, digital imaging, diagnostic applications and decision support applications. The use of dental Informatics seeks to support the mission of the Schools of Dentistry by providing strategic and technological planning services, implementing IT, and by coordinating with other entities. In addition, the IT in the dental fields also seeks to expand the field of dental Informatics through research, development of best practices, and the creation of new technology. The above construes are habitually applicable in the field of academic dental faculties in order to show the degree of candidates' performance in dentistry. The dental informatics provides the dentist with the central repository of information about the diagnostic and treatment

() One of the most highly reliable devices based on IT is digital diagnostic radiography available in University Dental Hospital/ University of Mosul. 
information about the patient. The influence on the communication systems and IT may positively reshape the interaction of the faculty member with the global excessive progress. What is related to the Internet category in the academic methods, the usage of Web world wide categories includes the applications and interfaces assessed by the academic theories in order to yield a new technology that affect the quantity and quality of the dental treatment that patients can obtain. The Web existence in the faculty and the abundance of new academic aids are required for the faculty members to update their information about the aspects of the dental care clinically. The advent of communication and information technologies has greatly affected the way in which health care is delivered. The convergence of communication and information technologies with biomedical informatics offers an opportunity to affect the faculty members performance and the next generations of dentists' practice used in terms of IT (Kirshner, 2003:5; Cf. Ismaeel, et al, 2006, 61).

Hence, dental Informatics can be defined as the application of computer and information science to improve dental practice, research, and program administration. Numerous applications that support clinical care, education, and research have been developed. Dental informatics is beginning to exhibit the characteristics of a discipline, such as a core literature, well trained specialists, and educational programs (Spallek, 2002,1).

The IT is to serve as the focus for individuals and organizations with interest or involvement in health care with an emphasis on dental informatics. To serve as a means of communication with other health care and informatics specialties to better improve all health care applications. The faculty members' emphasis is on the sharing of expertise and experiences in the use of dental information systems, computer technology, and communications to improve patient care, research and education. The symbolic representation, from which textual extracts are derived, can be used in conjunction with software for managing medical, dental, chemotherapy, nuclear medicine and education (cf. Hummond, et al, 2000,1). The use of IT helps in developing the innovation and creativity in the several of specialization (Al-Taweel and Rasheed, 2005,17).

As a field of study, dental informatics incorporates the knowledge of the health sciences with computer sciences, engineering and biomedical information science and biostatistics. Dental informatics is an interdisciplinary science that involves both the conceptual and clinical tools from these diverse disciplines for the understanding, invention, generation and propagation of diagnostic and medical information to solve complex problems in prevention and treatment of diseases, health care, health sciences and pharmaceutical research, education, clinical/medical decisionmaking, and delivery of health care. As such biomedical informatics is an essential element of 21 st-century health and medical sciences the workshops 
include the theoretical foundations and the current range of applications of computer aided informatics within contemporary dental sciences, and health care systems (Hutton, et al., 2000; Hammond, et al., 1993).

\section{Materials and Methods}

\section{Demographic and Academic Information}

Elite of 40 Dental Faculty members have been subjected to the type of scrutiny in this study as sampling the materials and methods. Both sexes are calculated in $(30 \%)$ for females and $(70 \%)$ for males in the Faculty. The age group percentages vary with respect to less or equal 30 years is $(28 \%), 31$ 40 years $(32 \%), 41-50$ years is $(25 \%)$ and $51-60$ years is $(15 \%)$.

The academic posts of the faculty members with their percentages are about the following:
a. $(2.5 \%)$ Professor
b. $(23 \%)$ Assistant Professor
c. $(12 \%)$ Lecturer
d. $(63 \%)$ Assistant Lecturer

The members are certainly differing in their years of working service that may be about three years into thirty-four years formal working service. As it is stated in following table:

\begin{tabular}{|c|c|c|c|}
\hline \multicolumn{4}{|c|}{$\begin{array}{c}\text { Table } 1 \\
\text { The Strategy of Data Collection }\end{array}$} \\
\hline \multicolumn{4}{|c|}{ Total Percentage: $40 \%$} \\
\hline \multicolumn{4}{|c|}{ Sex: } \\
\hline \multicolumn{2}{|c|}{ Males: $70 \%$} & \multicolumn{2}{|c|}{ Females: $30 \%$} \\
\hline \multicolumn{4}{|c|}{ Age Group } \\
\hline $\begin{array}{c}\text { Less or equal } 30 \\
\text { years: } 28 \% \\
\end{array}$ & $31-40$ years: $32 \%$ & $41-50$ years: $25 \%$ & 51-60 years: $15 \%$ \\
\hline \multicolumn{4}{|c|}{ Scientific Posts } \\
\hline Professor: $2 \%$ & $\begin{array}{c}\text { Assistant Professor: } \\
23 \% \\
\end{array}$ & Lecturer: $12 \%$ & $\begin{array}{c}\text { Assistant Lecturer: } \\
63 \% \\
\end{array}$ \\
\hline \multicolumn{4}{|c|}{ Years of Working Service: 3 - 34 years } \\
\hline \multicolumn{4}{|c|}{ Nationality: Iraqi } \\
\hline
\end{tabular}

In the context of this strategy we will tackle several templates to manage the evaluation, the essential information needs and the training courses in the in the academic fields of teaching methods. Hence, IT will be manifested in the Training information needs on the one hand and the IT needs on the other. Each of which will be analyzed individually in our discussion. 


\section{Discussion}

The designing of computer simulation is suitable for analyzing medical and dental health care problems for constructing solutions to optimize decisions concerned with efficacy of information transfer, productivity and resource utilization in a health care facility.

\section{Training and Information Needs}

The design and implement computer-based multimedia educational and training systems (e.g., interactive CD-ROM, Web-based educational programs and intraoral diagnostic digital cameras) for intelligent tutoring, self-paced learning, staff development, improving the clinical decisionmaking on selected topics among the faculty members.

The responds of the faculty members are on which the additional training is preferred and suggested to receive additional training via short courses/ workshops. More than (5) choices are acceptable and encouraged by the respondents of the topical areas of questionnaires respectively. The Research Method obtained a high-score that reached in percentage into $(80 \%)$ of total choices. While, the basic Bio-Static are of $(80 \%)$ among the respondents. The Computer-Aided Design is of $(50 \%)$ among the total choices. Finally the Scientific Presentation is of $(35 \%)$. The priority in the choices is shown in Table (1):

Table 2

The Selection of the Ranks

\begin{tabular}{|c|c|c|c|c|c|}
\hline \multirow{3}{*}{ Topical Areas } & \multicolumn{5}{|c|}{ Rank Selection } \\
\hline & $1 \mathrm{st}$ & 2nd & $3 \mathrm{rd}$ & 4th & 5th \\
\hline & (\%) & $(\%)$ & $(\%)$ & (\%) & (\%) \\
\hline Basic Bio-Statistic & 6 & 3 & 3 & 9 & 9 \\
\hline Research Method & 17 & 23 & 30 & 13 & 0 \\
\hline Computer Aided Design & 30 & 10 & 30 & 15 & 0 \\
\hline Computer Modeling & 25 & 6 & 12 & 6 & 25 \\
\hline Scientific Presentation & 7 & 42 & 21 & 7 & 7 \\
\hline
\end{tabular}

As for the most suggested computer software modeling and programs for training to be received by the faculty members specified the kinds of the training and refresher courses. The respondents of the questionnaire also indicated the training level they would like to join. This may refer the increasing need by the responds for updating their experience in the IT for the academic and research targets. Table (2) shows the following details: 


\begin{tabular}{|c|c|c|c|c|}
\hline \multicolumn{5}{|c|}{$\begin{array}{c}\text { Table } 3 \\
\text { Computer Levels of Training }\end{array}$} \\
\hline \multirow{2}{*}{ Computer Software } & Beginners & Intermediate & Advance & Total \\
\hline & $(\%)$ & $(\%)$ & $(\%)$ & $(\%)$ \\
\hline Word Processing & 8 & 32 & 20 & 60 \\
\hline Database Management & 13 & 20 & 5 & 38 \\
\hline Communication Software & 11 & 14 & 15 & 40 \\
\hline Data Analysis Software & 17 & 17 & 11 & 45 \\
\hline Spreadsheet & 10 & 5 & 3 & 18 \\
\hline Presentation Software & 20 & 12 & 3 & 35 \\
\hline Basic Computer Skills & 26 & 0 & 0 & 26 \\
\hline
\end{tabular}

Word Processing, for instance, we possibly find habitually the deviation made by the faculty members into the training courses. The ratio is of $60 \%$. As for $8 \%$ of the total numbers wish to receive a training course in terms of the primary or beginning sector of training methodology. While $32 \%$ choose the intermediate sector of training methodology. On the final state, $20 \%$ prefer to join the advanced sector of training methodology.

Figure (1) states the deviation of faculty members for these academic programs via the following histogram:

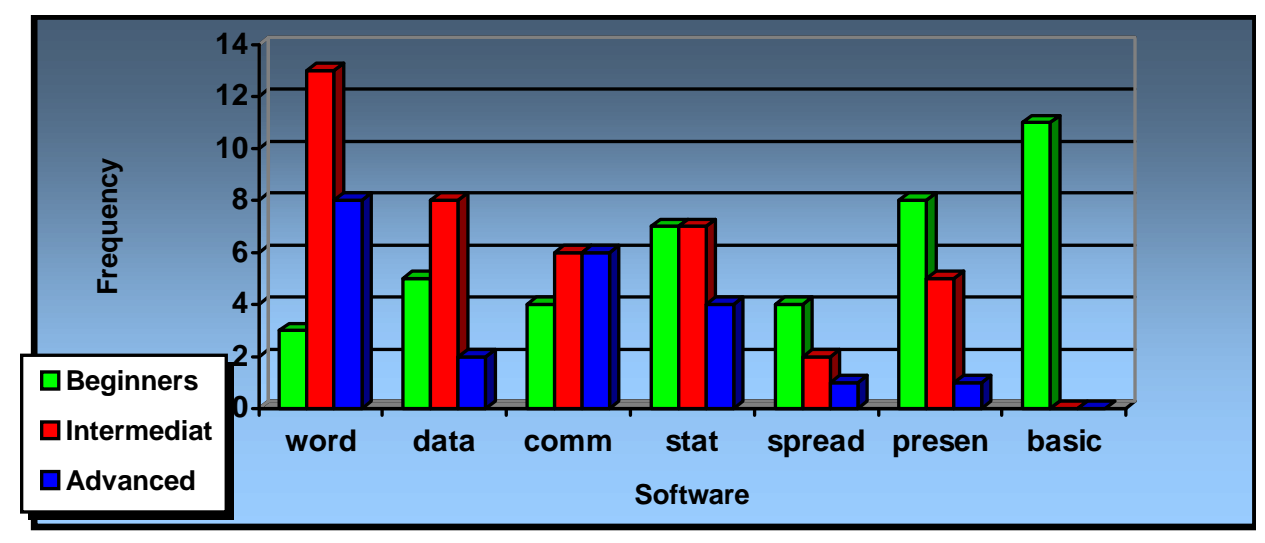

Figure 1

A Histogram of Faculty members Deviation of Using Academic Computer Programs

In another view, we found that the Faculty professors wish to receive software Database Management, Data Analysis Software and Spreadsheet in 
the intermediate level. While, the assistant professors suggest join the training on Word Processing software and Communication Software on the intermediate level of training. The ratio in this aspect is (30\%). While on Database Management and Presentation Software is (20\%). Data Analysis Software is $(10 \%)$. The training on the beginners' level is binaurally shared between Word Processing and Presentation Software with (20\%). Communication Software, Data Analysis Software and Spreadsheet are (10\%). Hence, this notion is applicable for all academic posts on the one hand and the kinds, nature and levels of the software programs as it scheduled:

\section{Table 4}

The Preference of Faculty members to the Types of Courses

\begin{tabular}{|c|c|c|c|c|c|c|c|c|c|c|c|c|}
\hline \multirow{2}{*}{ Computer Software } & \multicolumn{3}{|c|}{ Professor } & \multicolumn{3}{|c|}{$\begin{array}{l}\text { Assistant } \\
\text { Professor }\end{array}$} & \multicolumn{3}{|c|}{ Lecturer } & \multicolumn{3}{|c|}{ Assistant Lecture } \\
\hline & B & $\mathbf{I}$ & $\mathbf{A}$ & B & I & $\mathbf{A}$ & B & $\mathbf{I}$ & $\mathbf{A}$ & B & $\mathbf{I}$ & $\mathbf{A}$ \\
\hline Word Processing & - & - & - & 20 & 30 & 10 & 20 & 20 & 20 & - & 38 & 25 \\
\hline Database Management & & 100 & & & 20 & - & - & 80 & - & 21 & 4 & 8 \\
\hline Communication Software & - & - & - & 10 & 30 & - & 40 & - & 20 & 13 & 13 & 21 \\
\hline Data Analysis software & . & 100 & - & 10 & 10 & 10 & - & - & - & 17 & 21 & 4 \\
\hline Spreadsheet & - & 100 & - & 10 & - & - & 20 & - & - & 13 & 4 & 4 \\
\hline Presentation Software & - & - & - & 20 & 20 & - & 20 & - & - & 21 & 13 & 4 \\
\hline Basic Computer Skills & - & - & - & - & - & - & - & - & - & 42 & - & - \\
\hline
\end{tabular}

The Faculty member's respondents were asked if they joined any training workshops, seminars or refresher courses. The responds involved the following:

\section{Inside Iraq:}

a. (32\%) Faculty respondents only joined these types of courses and seminars.

b. (33\%) Faculty respondents agreed positively the validity of these courses and seminars.

2. Outside Iraq:

c. (7\%) Faculty respondents joined these types of courses and seminars.

d. (20\%) Faculty respondents agreed positively validity of these courses and seminars.

Generally speaking, the respondents are able to receive an additional training and refresher courses, but they show preference to a specific method than others. So, their opinions are variously managed by the responding percentages. As in the following percentages: 
a. Sixty-two percent (62\%) of Faculty respondents selected the training by workshop method.

b. Seven percent $(7 \%)$ of Faculty respondents selected the training by seminar method.

c. Twenty-three percent (23\%) of Faculty respondents selected the training by refresher courses.

The efficacy and the benefit of training workshops are significant in $(65 \%)$ of the total faculty members. The training seminars are less significant in $(57 \%)$ of the totality. In the final version, the selection ratio is lesser than the previous items; the rate of efficacy and benefit of the refresher courses are only (52\%).

The above discussion can be clarified in the following figure:

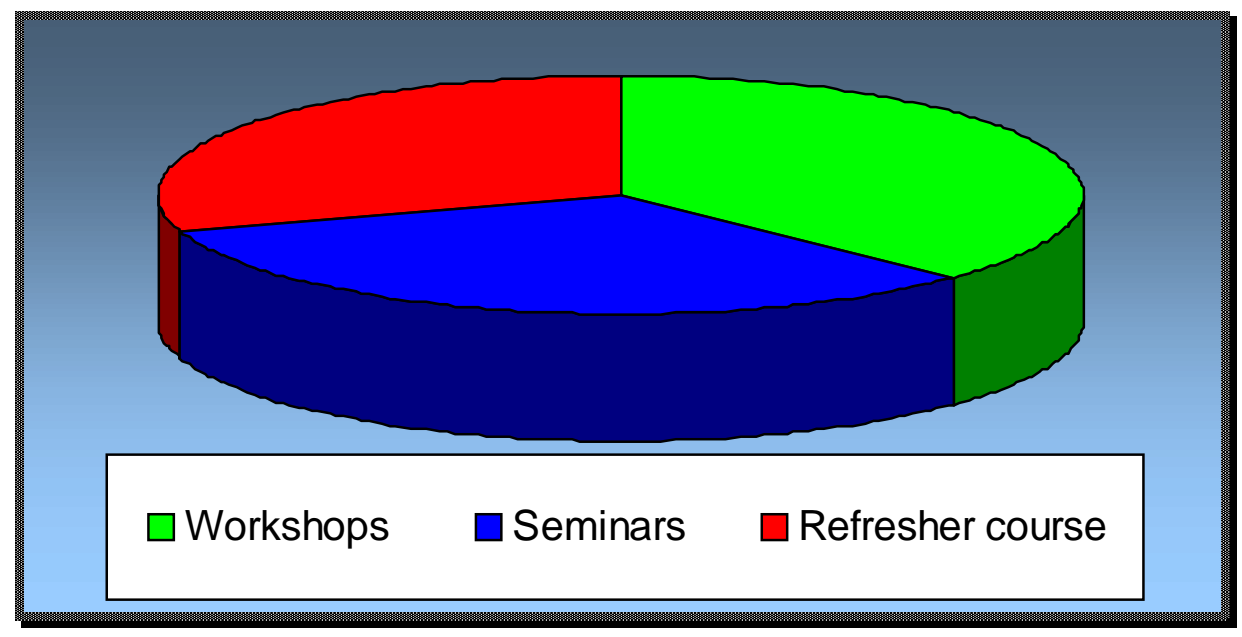

Figure 2

The Faculty Members Preference of Receiving the Additional Training

\section{Information Technology Needs}

Computers are considered to be one of the technical methods that supposed to be valuable by all faculty members in all academic posts and profession. Thus, the study spotlights on this aspect as a negotiable field of technical requirement to promote the clinical and pedagogical modules. The utilization of computational approaches and modern computer-based techniques are required in the fields of digital radiography, intra-oral designs, diagnosis and cephalometric modules to solve the complex dental clinical problems and to come up with modern strategies of scientific research.

To start with, through the process of evaluating the level of using computers by the teaching staff in the University first and in the Faculty second, it is resulted that the computing usage indicator does not exceed 30 
minutes daily. Sometimes, computers are habitually used for the web-site needs to meet the requirements of the academic and research purposes.

The following indicator shows the assessments of the computing usage matters:

Table 5

The Assessment of Computer Usage Matters

\begin{tabular}{|l|c|c|c|c|c|}
\hline \multirow{2}{*}{ Location } & \multicolumn{5}{|c|}{ Level of Access } \\
\cline { 2 - 6 } & $\begin{array}{c}\text { No Access } \\
(\boldsymbol{\%})\end{array}$ & $\begin{array}{c}\text { Not Easy } \\
(\boldsymbol{\%})\end{array}$ & $\begin{array}{c}\text { Mod Easy } \\
(\boldsymbol{\%})\end{array}$ & $\begin{array}{c}\text { Easy } \\
(\boldsymbol{\%})\end{array}$ & $\begin{array}{c}\text { Easy Access } \\
(\boldsymbol{\%})\end{array}$ \\
\hline In Computer Faculty & 35 & 23 & 4 & 20 & 7 \\
\hline In Computer University & 27 & 15 & 9 & 12 & 18 \\
\hline
\end{tabular}

We can notice above, that the indicator No Access constitutes (35\%) of the group opinions of faculty respondents as a level of computing usage in the Faculty. While, a level of computing usage in the University is naturally (27\%) and this is consequently significant on the academic level. Thus, Dental faculty has prominently a high percentage of No Access in comparison with the University level of Computer Access.

As for the indicator Easy Access constitutes (7\%) of the computing usage levels among the Faculty respondents and (18\%) as a computing usage level in the University. Hence, the network connections are mostly required nowadays specially among the academic staff, in order to keep coming with the modern technologies in the worldwide. Hence, the questionnaire included asking if the faculty member respondents have a network access in the Faculty Lab, the University General Lab, or at Home. The answers were scheduled in Table (5). This table shows that (12\%) of the faculty members respondents have the access connection in their offices and $(7 \%)$ of faculty members respondents have the access connection with the University General Lab. But $(65 \%)$ of the faculty members respondents have the home net access connection.

Table 6

The Percentages of Net Access

\begin{tabular}{|l|c|c|}
\hline \multirow{2}{*}{ Location } & \multicolumn{2}{c|}{ Net Access } \\
\cline { 2 - 3 } & YES (\%) & NO (\%) \\
\hline Office Access & 12 & 88 \\
\hline Faculty Lab Access & 0 & 100 \\
\hline General Lab Access & 7 & 93 \\
\hline Home Access & 65 & 35 \\
\hline
\end{tabular}

As for the technical method practiced by the faculty members is the Statistical/Data Analysis as a most prominent method widely used, the level of delineating this method reached to an expertise user (29\%) of the total 
faculty respondents. The second method includes e-mail connections with $(11 \%)$; followed by Word Processing with $(8 \%)$ and finally Internet Search with $(5 \%)$, as tabulated bellow:

Table 7

The Percentages of Computer Services

\begin{tabular}{|l|c|c|c|c|}
\hline \multirow{2}{*}{\multicolumn{1}{|c|}{ Technologies }} & \multicolumn{4}{c|}{ Level of Using } \\
\cline { 2 - 5 } & $\begin{array}{c}\text { Do Not Use } \\
(\mathbf{\%})\end{array}$ & $\begin{array}{c}\text { New User } \\
(\boldsymbol{\%})\end{array}$ & $\begin{array}{c}\text { Intermediate User } \\
(\boldsymbol{\%})\end{array}$ & $\begin{array}{c}\text { Expert User } \\
(\boldsymbol{\%})\end{array}$ \\
\hline Word Processing & 40 & 25 & 27 & 8 \\
\hline Presentation Software & 65 & 15 & 20 & 0 \\
\hline Spreadsheets & 80 & 10 & 10 & 0 \\
\hline Statistical/Data Analysis Software & 52 & 17 & 2 & 29 \\
\hline E-mail Connections & 47 & 25 & 17 & 11 \\
\hline Internet Searching & 55 & 30 & 10 & 5 \\
\hline Web-Page Development & 85 & 15 & 0 & 0 \\
\hline Network Distribution of Class materials & 82 & 15 & 2 & 1 \\
\hline Using Multimedia Software & 85 & 7 & 5 & 3 \\
\hline Creating Multimedia Software & 77 & 15 & 5 & 3 \\
\hline Using Multimedia in Classrooms & 87 & 5 & 5 & 3 \\
\hline Distance Learning & 87 & 5 & 7 & 1 \\
\hline Video Conferencing Technologies & 80 & 15 & 5 & 0 \\
\hline Computer Simulations in Exercises & 87 & 7 & 5 & 1 \\
\hline
\end{tabular}

The most essential note can be raised in the context of the above tables, is that the readiness responded by $(100 \%)$ of the Dental academic staff to receive further training in order to develop their technical skills on the one hand and to update information reaching expertise user. As tabulated bellow:

\section{Table 8}

The Percentages of Further Training

\begin{tabular}{|c|c|c|c|c|c|c|c|c|}
\hline \multirow{3}{*}{ Technologies } & \multicolumn{8}{|c|}{ Enhance or Not with Technology } \\
\hline & \multicolumn{2}{|c|}{$\begin{array}{c}\text { Do Not Use } \\
(\%)\end{array}$} & \multicolumn{2}{|c|}{$\begin{array}{c}\text { New User } \\
(\%)\end{array}$} & \multicolumn{2}{|c|}{$\begin{array}{c}\text { Intermediate User } \\
(\%)\end{array}$} & \multicolumn{2}{|c|}{$\begin{array}{c}\text { Expert User } \\
(\%)\end{array}$} \\
\hline & Yes & No & Yes & No & Yes & No & Yes & No \\
\hline Word Processing & 56 & 44 & 90 & 10 & 45 & 55 & 100 & 0 \\
\hline Presentation Software & 53 & 47 & 50 & 50 & 62 & 38 & - & - \\
\hline Spreadsheets & 43 & 57 & 100 & 0 & 75 & 25 & - & - \\
\hline Statistical/Data Analysis Software & 52 & 48 & 85 & 15 & 100 & 0 & 90 & 10 \\
\hline E-mail & 47 & 53 & 90 & 10 & 85 & 15 & 100 & 0 \\
\hline Internet Searches & 54 & 46 & 75 & 25 & 100 & 0 & 100 & 0 \\
\hline Web-Page Development & 55 & 45 & 83 & 17 & - & - & - & - \\
\hline Network Distribution of Class Materials & 48 & 52 & 66 & 34 & 100 & 0 & - & - \\
\hline Using Multimedia Software & 47 & 53 & 0 & 100 & 100 & 0 & 100 & 0 \\
\hline Creating Multimedia Software & 41 & 59 & 100 & 0 & 100 & 0 & 100 & 0 \\
\hline Using Multimedia in Classrooms & 42 & 58 & 100 & 0 & 100 & 0 & 100 & 0 \\
\hline Distance Learning & 40 & 60 & 50 & 50 & 66 & 34 & - & - \\
\hline Video Conferencing Technologies & 43 & 57 & 66 & 34 & 100 & 0 & - & - \\
\hline Computer Simulations in Exercises & 45 & 55 & 100 & 0 & 100 & 0 & - & - \\
\hline
\end{tabular}


It can be noted here that faculty members have a hectic ability to refresh their technical information in order to intercept the classroom needs with the new technology for their students. They are in a complete awareness of the excessive development in technology as well as the modern methods in their fields of study. Their understanding is to keep coming with the modern IT such as the new materials, equipment, instruments and the modern theories whether they are basic or applied of dental sciences. They comprehend the necessity using the computing systems programs and aids with their dental research fields. The usage of the modern technical methods helps in assessing and evaluating the most recognizable issues and cases in the academic research study, medical and dental static analysis.

This concept can be manifested in the following figure:

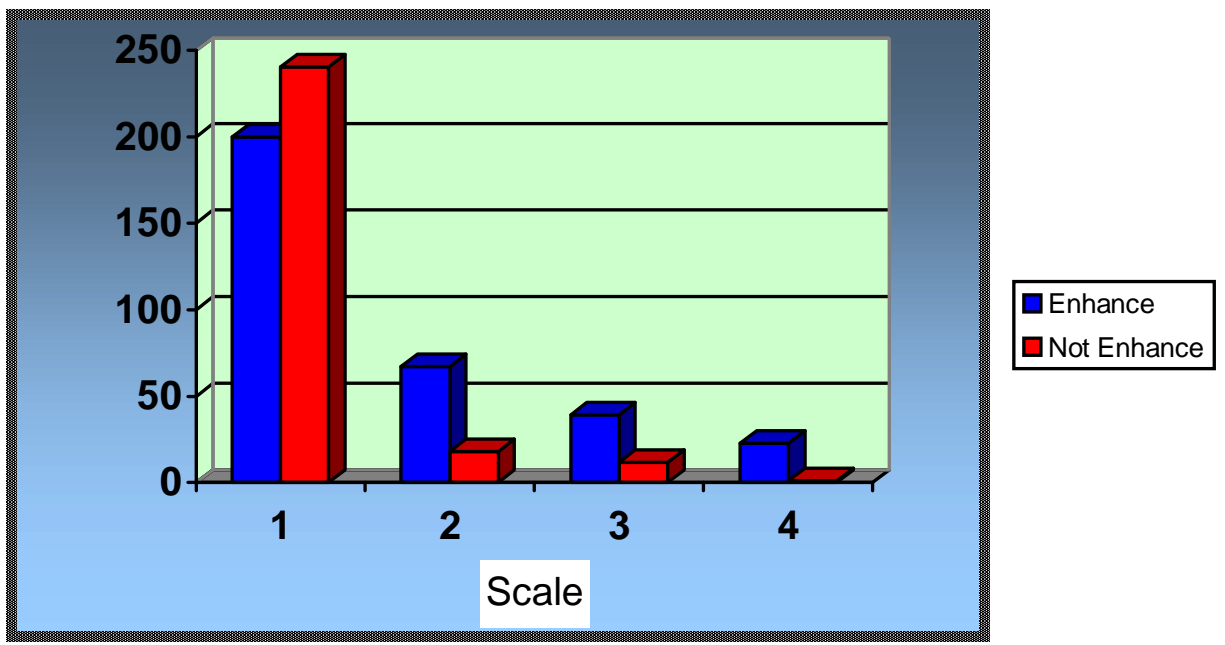

Figure 3

A Histogram of the Acceptability Using the Computer Programs in the Dental Field

In order to be aquatinted with the obstacles blocking the way of the effective usage in the field of IT; the faculty members were demanded to specify the major hinders of stepping out the axioms of Software, Familiarity and Support.

As for the most magnificent obstacles in Software axiom is as follows with percentages:

a. Forty eight percent (48\%) suggested that desktop computer is not connected to network in the Faculty.

b. Forty - five percent (45\%) indicated the difficulty of transferring classroom-lecture information and the outdated software. 
c. Forty percent (40\%) referred to the shortage of the academic prerequisites and equipment to display (IT) in the classrooms or lecture halls.

There are three obstacles may hinder the way of applying (IT) in the field of Familiarity axiom, they are as follows:

a. Sixty - eight percent $(68 \%)$ focused on the lack of updating the training methods in IT.

b. Forty - five percent (45\%) specified the absence of valuable references and resources in the field teaching the specialized discipline.

c. Thirty - five percent (35\%) stated the shortage of applicable resources on the experience of using IT.

There are other three obstacles for the Support axiom. They are as follows:

a. Fifty - three percent (53\%) agreed that insufficient financial support from the University administration Units.

b. Forty - five percent (45\%) demonstrated the difficulty to obtain any support outside the normal working hours in the faculty.

c. Forty percent $(40 \%)$ provided that not all the academic students have the access to the e-mail and Internet accesses.

As for the technical knowledge in the educational and academic training modules, it is found that $(5 \%)$ of faculty members respondents see that there is no importance for the technical expertise usage in the academic process. While, (14\%) tends to use the interception of the technical information with the academic process is that of great difficulty and not an easy matter. The importance of applying the technical information in the academic process is inferred by $(81 \%)^{\star}$.

Finally, when the students in their aspect were asked about their own technical needs, the answers grouped as follows:

a. More practice on various computer programs is required.

b. The need to highly condensed practical modules on the application of the Internet and e-mail usage services.

c. The simulation of practical implications of the subject matter on technical standards.

d. The vast difference in the computer programs that should be transferred systematically.

e. Short-time workshops in the field of technical information and dental computing.

f. Developing the skills on the subject of dental informatics, biomedical and biotechnical considerations.

( ${ }^{*}$ The academic process in the Dental Faculty conferred in the theoretical, practical and clinical training. 
g. The need for a professional training on computers.

h. An accurate analysis for the techniques of statistical performance.

i. Developing computing systems and solutions that will help to design more effective and more informative clinical trials to cut years out of development process.

j. The need for a well- trained specialists in the field of technology and computers.

\section{Conclusions}

This study concludes the following points:

1. IT offers the potential to expand access to training health care significantly in the field of dentistry, to improve its quality, to reduce the academic literacy, and to transform the conduct of biomedical research.

2. The intermediate and advanced workshops are workable to develop the IT awareness and acquaintance in the field of specialization and scientific research in the faculty.

3. The study agrees objectively for the faculty members to join the refresher courses in the field of IT.

4. The study observed that the faculty respondents are ready to intercept the technological modules with the academic operation in the faculty. The workshops are of great benefit for the faculty members to get aquatinted with the usage of the IT. Much work remains to be done if the tools we are developing are going to be practicable and acceptable to researchers.

5. The faculty respondents understand the importance of the modern technology in the teaching and training process.

6. IT provides research-related employment opportunities for the faculty members as cooperative research groups technologies as in terms of the academic standards.

\section{References}

\section{Arabic References:}

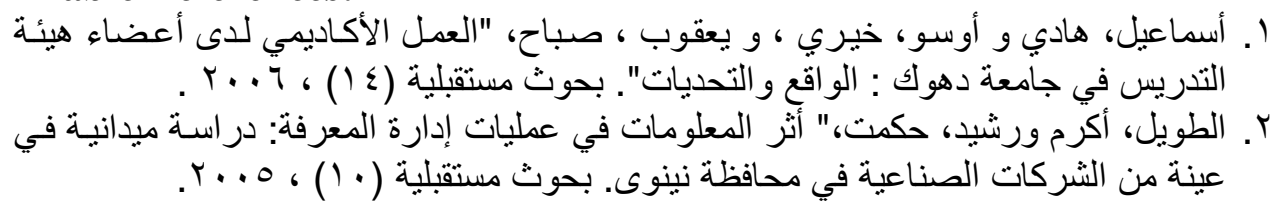

\section{English References}

1. Fortier, J. Potter, C. Grady, S., Lohr, N., Klein, N., Wisconsin's Model Academic Standards for Information and Technology Literacy. John T. Benson: Wisconsin, 1998.

2. Hammond P., Davenport J., Fitzpatrick F., "Logic-Based Integrity Constraints and the Design of Dental Prostheses". Artificial Intelligence in Medicine, 1993.

3. Hovenm, J. and Lockhorst, G., "Deontic Logic and Computer- Supported Computer Ethics". Metaphilosophy LLC and Blackwell Publishers Ltd. 33, (3), 2002. 
4. Hummond, P., Modgil, S. and Wyatt J., "Safety and Computer Aided Design of Chemotherapy Plans". Topics in Health Information Management on Human Error and Clinical Systems. Health Management Center: London, 2000.

5. Hutton, J., Cunningham, S. and Hammond, P., An Evaluation of Active Shape Models for the Automatic Identification of Cephalometric Landmarks. European Journal of Orthodontics. 12, 2000.

6. Kirshner, M., "The Role of IT and the Research in the Dentist-Patient Relationships". International and American Associations for Dental Research, 2003.

7. Reddy, R., Wladawsky, I., and Benhamou, E., "Transferring Health Care through Information Technology". President's Information Technology Advisory Committee. Executive Office: USA, 2001.

8. Spallek H., Dental Informatics: A Frontier Discipline in Dentistry? 13th International Alexandria Dental Congress, 2002.

9. Steel, R. and Torrie, J., Principles and Procedures of Statistics: A Biometrics Approach. MacGraw-Hill International Editions, 1981. 